\title{
Using Blue Intensity from drought-sensitive Pinus sylvestris in Fennoscandia to improve reconstruction of past hydroclimate variability
}

\author{
Kristina Seftigen $^{1,2,3}$ - Mauricio Fuentes ${ }^{1} \cdot$ Fredrik Charpentier Ljungqvist $^{4,5,6} \cdot$ Jesper Björklund $^{3}$
}

Received: 6 December 2019 / Accepted: 4 May 2020 / Published online: 13 May 2020

(c) The Author(s) 2020

\begin{abstract}
High-resolution hydroclimate proxy records are essential for distinguishing natural hydroclimate variability from possible anthropogenically-forced changes, since instrumental precipitation observations are too short to represent the whole spectrum of natural variability. In Northern Europe, progress in this field has been hampered by a relative lack of long and truly moisture-sensitive proxy records. In this study, we provide the first assessment of the dendroclimatic potential of Blue Intensity (BI) and partial ring-width measurements (latewood and earlywood width series) from a network of cold and droughtprone Pinus sylvestris L. sites in Sweden. Our results show that all tree-ring parameters and sites share a clear and strong sensitivity to warm-season precipitation. The $\Delta \mathrm{BI}$ parameter, in particular, shows considerable potential for hydroclimate reconstructions, here permitting a cross-validated precipitation reconstruction capable of explaining 56\% (1901-2010 period) of regional-scale warm-season high-frequency precipitation variance. Using $\Delta \mathrm{BI}$ as an alternative to ring-width improves the predictive skill with nearly a 20 percentage points increase in explained variance, reduces signal instability over time as well as allows a broader seasonal window (May-July) to be reconstructed. Additionally, we found that earlywood BI also reflect a positive late winter through early summer temperature signal. These findings emphasize that tree-rings, and in particular wood density parameters such as from BI, are capable of providing fundamental information to advance our understanding of hydroclimate variability in regions with a cool and rather humid climate regime that traditionally has been overlooked in studies of past droughts. Increasing the spatio-temporal coverage of hydroclimate records in northern Europe, and taking full advantage of the opportunities offered by the wood densitometric properties should be considered a research priority.
\end{abstract}

Keywords Dendroclimatology $\cdot$ Tree-ring $\cdot$ Blue Intensity $\cdot$ Scots pine $\cdot$ Hydroclimate $\cdot$ Fennoscandia $\cdot$ Drought sensitivity

Electronic supplementary material The online version of this article (https://doi.org/10.1007/s00382-020-05287-2) contains supplementary material, which is available to authorized users.

Kristina Seftigen

kristina.seftigen@gvc.gu.se

1 Regional Climate Group, Department of Earth Sciences, University of Gothenburg, Gothenburg, Sweden

2 Georges Lemaître Centre for Earth and Climate Research (TECLIM), Earth and Life Institute, Université Catholique de Louvain (UCL), Louvain-la-Neuve, Belgium

3 Swiss Federal Institute for Forest Snow and Landscape Research WSL, Birmensdorf, Switzerland

4 Department of History, Stockholm University, Stockholm, Sweden

5 Bolin Centre for Climate Research, Stockholm University, Stockholm, Sweden

6 Swedish Collegium for Advanced Study, Uppsala, Sweden

\section{Introduction}

The drought vulnerability of the usually cool and wet region of northern Europe was highlighted in the extreme 2018 summer drought. The prospect of future global-scale climate change modifying exposure to drought warrants the urgent need for a better understanding of regional drought dynamics, associated physical mechanisms, and the range of conditions that can be expected in the future, as a sound basis for the successful implementation of mitigation and adaptation strategies (Toreti et al. 2019; Trnka et al. 2018). This includes a robust understanding of the sensitivity of the climate system to different forcings. However, achieving such understanding is not straightforward due to the chaotic nature of intrinsic climate variability, which in the short-term, as well as on decadal and longer time scales can amplify or dampen forced trends and signals (Ljungqvist 
et al. 2016, 2019). These constraints present challenges in our ability to separate the role of anthropogenic forcing, natural forcing, and long-term natural variability in post-industrial hydroclimate change (Barnett et al. 2005). Establishing a baseline variability unperturbed by significant anthropogenic forcing over decadal-to-centennial time-scales therefore require a perspective that can be obtained only from pre-industrial hydroclimate information (Cook et al. 2004, 2015, 2016; Marvel et al. 2019).

Climate reconstructions over the Common Era (CE) in Scandinavia rely heavily on information derived from treering data. This region is, in fact, one of the most prominent regions in the world for high-quality tree-ring based temperature reconstructions (Esper et al. 2016, 2018; Linderholm et al. 2015; St. George and Ault 2014). It is, moreover, evident from the literature that wood density of the latewood, maximum density (MXD), is particularly skillful in characterizing past temperature changes over the past one to two millennia (e.g., Björklund et al. 2019). There are numerous advantages of MXD over tree-ring width (TRW) as a climate proxy. MXD generally contains a stronger climate signal with higher signal-to-noise ratios (Ljungqvist et al. 2020a), shows less biological persistence (Esper et al. 2015) and age-related signal-muting (Konter et al. 2016), and is less influenced by stand disturbances (Rydval et al. 2018). Past hydroclimate of Fennoscandia has attracted less attention (Linderholm et al. 2010, 2018), but studies using TRW have been surprisingly successful considering the cold to mild/humid climate of the region (e.g., Drobyshev et al. 2011; Helama et al. 2009; Seftigen et al. 2015a; Seftigen et al. 2013). Considering the success of wood densitometric parameters in studying past temperatures, it is the logical next step to explore whether the density of drought-sensitive trees of the region similarly can improve or complement our understanding of past hydroclimate variability in Scandinavia. In fact, wood density of the earlywood has been shown to carry a pronounced precipitation signal in drier climates of the Iberian Peninsula, southwestern United States and Siberia (Camarero et al. 2014, 2017; Cleaveland 1986).

Wood densitometric parameters can be derived using several different measurement techniques: X-ray based densitometry, cell anatomically-based densitometry or simply from the reflection of visible light from carefully prepared wood surfaces (Björklund et al. 2019). Although these various techniques differ in measurement resolution, reliable results can be obtained at inter-annual to multi-decadal timescales with low-cost techniques using a commercial flatbed scanner to generate image of reflected or absorbed blue light variation in wood (BI; McCarroll et al. 2002). In an exploratory study, where low cost, speed and sufficient accuracy all are important features; BI-based wood density estimations become very attractive.

Building upon previous tree-ring based drought research in Fennoscandia (Seftigen et al. 2015a, b, 2017), this article provides the first exploration of BI (including maximum latewood BI, average earlywood BI, and delta BI) and partial ring-width measurements (earlywood and latewood widths) from a network of cool and drought-prone Pinus sylvestris sites in southern and central Sweden (latitudes $57^{\circ}-62^{\circ}$ N; Fig. 1). This study assess the dendroclimatic potential
Fig. 1 Geographical distribution of the five tree-ring chronology sites in Sweden, together with the outline of the 57-62 $\mathrm{N} / 14-19^{\circ}$ E subset of the CRU TS 4.03 product (Harris et al. 2014) and the location of the Stockholm historical weather observatory dataset used in the calibration/validation exercise

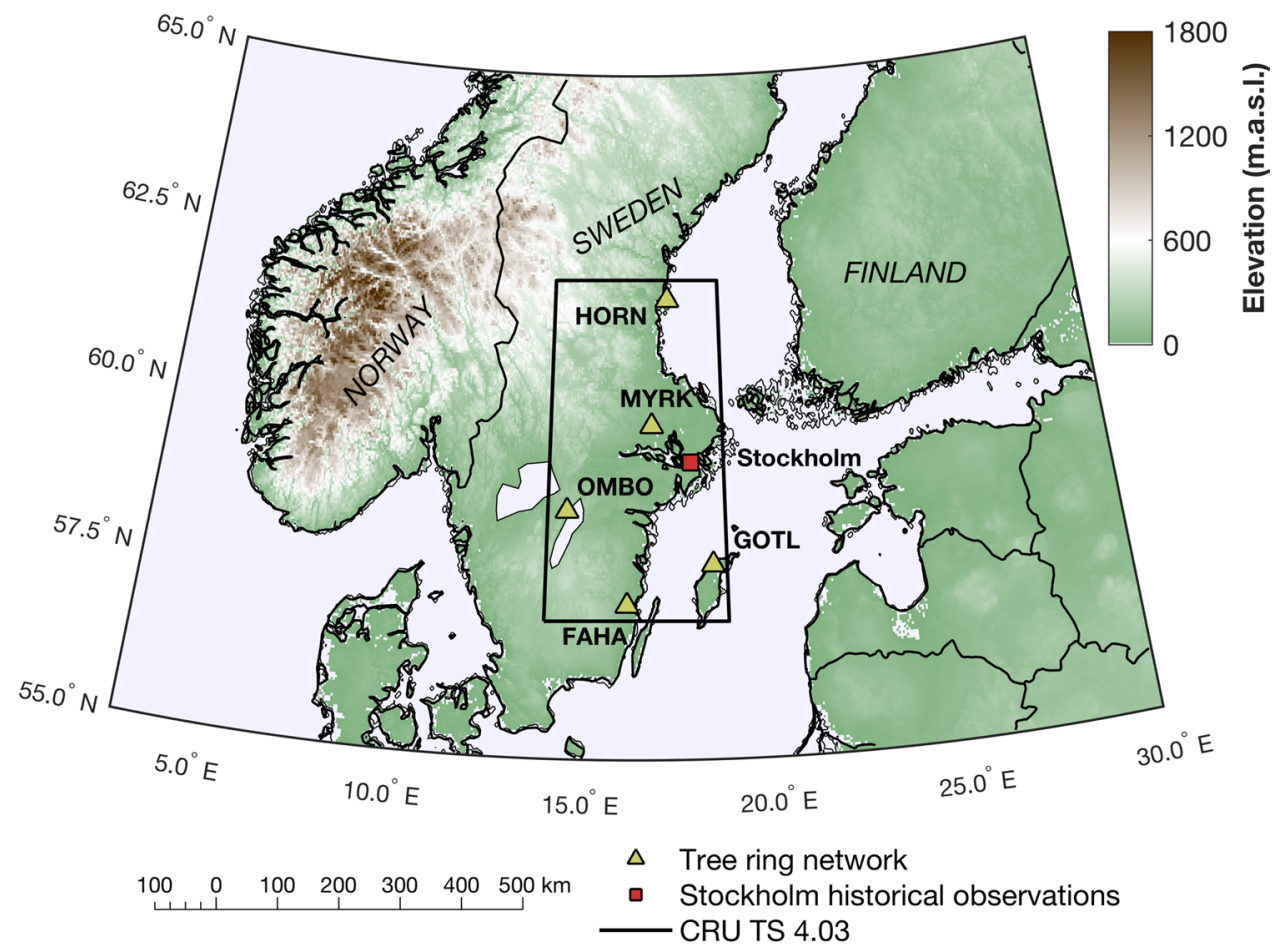


of these sub-annual parameters by evaluating the nature, strength and temporal stability of their seasonal climate signal. In particular, we are interested in whether utilizing information from this tree-ring proxy ensemble may yield more robust hydroclimate reconstructions than prior reconstructions based only on ring-width. If these parameters indeed can provide superior or complementary information, they would be a critical resource to bridge some of the current spatiotemporal data gaps of high-resolution hydroclimate proxy data across northern high latitudes, recently highlighted in the review by Linderholm et al. (2018).

\section{Materials and methods}

\subsection{Chronology development}

For our study, we selected a subset of the tree-ring network presented in (Seftigen et al. 2015a), consisting of five sites from Sweden that forms a $\sim 500 \mathrm{~km}$ north-south transect from latitudes $57^{\circ}$ to $62^{\circ} \mathrm{N}$ (Fig. 1). The annual mean temperature varies throughout the region between 2 and $7{ }^{\circ} \mathrm{C}$. The range for the warmest month of the year, July, is $13{ }^{\circ} \mathrm{C}$ and $18{ }^{\circ} \mathrm{C}$ and for the coldest month, February, between -1 and $-9{ }^{\circ} \mathrm{C}$ over the reference period 1961-1990. The mean daily maximum temperature exceeds $20^{\circ} \mathrm{C}$ in most of the region during June-August, with maximum temperatures frequently exceeding $25^{\circ} \mathrm{C}$. Annual total precipitation varies throughout the region between $\sim 450$ and $\sim 800 \mathrm{~mm}$ over the same reference period. The driest time occurs in late winter to spring, with one fifth of the precipitation falling in February-May. The length of the growing season varies from over 200 days in the southeast to less than 140 days in the northwest. Tree-ring width (TRW) records of Scots pine (Pinus sylvestris L.) at these sites is documented to be particular sensitive to May-June precipitation and were, together with additional tree-ring collections, used previously to reconstruct gridded warm-season Standardized Precipitation-Evapotranspiration Index (SPEI; Vicente-Serrano et al. 2010) for the past millennium of the Common Era (Seftigen et al. 2017).

At each site, one to two $5 \mathrm{~mm}$ diameter cores were extracted from approximately 20 dominant or co-dominant living Scots pine trees for $\mathrm{BI}$ and partial ring width analyses (Table 1). Samples from dry microsites, characterized by rocky shallow soils, were selected to maximize the moisture signal in the tree growth. Middle-aged ( 100-200 years old) and young $(<100$ years) trees were specifically targeted for this study to avoid extremely narrow rings that were difficult to distinguish in older specimens. Core samples were placed in a Soxhlet apparatus and washed for approximately $24 \mathrm{~h}$ with 99\% ethanol to remove resins and extractives, whereupon they were surfaced with a core microtome (Gärtner and Nievergelt 2010) and subsequently polished with 1200 grit sandpaper to fill cell voids with white wood dust. This twotiered approach first ensures a flat surface and then maximizes the contrast, and thus the visibility of ring boundaries and cell structures prior to scanning. An Epson Expression 10000XL flatbed scanner, calibrated with SilverFast Ai scan software using the calibration target IT8.7/2, was used to produce digital images from the tree cores at 2400 dpi resolution (pixel size $\sim 10 \mu \mathrm{m}$ ). The BI and partial ring-width measurements were carried out in the software CooRecorder version 9.4 (Larsson 2014). The BI measurements, defined here as absorbed light intensities, yield values positively correlated with wood density. Both the earlywood and latewood portions of the rings were analyzed, where the parameters average earlywood BI (EWBI) and maximum latewood BI (MXBI) corresponds to earlywood density and MXD, respectively, from $\mathrm{X}$-ray based techniques (see table $\mathrm{S} 1$ in the supplement for CooRecorder program settings). Furthermore, we derived a third BI-parameter, defined as the difference between the MXBI and the EWBI parameters, called $\Delta$ BI (Björklund et al. 2014).

Visual cross-dating and measuring accuracy was checked with the program COFECHA (Holmes 1983). Note that the same cores and sample depths were used to produce the various parameter-level chronologies from each site. Thus, we did not omit from subsequent analyses accurately dated BI and partial ring width series exhibiting reduced correlations with the mean chronology. Because this study explores the potential of BI in a previously established, and now updated dataset, we focus our analyses on the high-frequency portion of variability.

We detrended the tree-ring data using 67-year cubic smoothing splines with a 50\% frequency cut-off (Cook and
Table 1 Summary of the site and chronology characteristics

\begin{tabular}{llllclll}
\hline Site & Site ID & Lat & Long & $\begin{array}{c}\text { Elevation } \\
\text { (m.a.s.l.) }\end{array}$ & \# of trees/series & Period > 5 series & $\begin{array}{l}\text { Mean segment } \\
\text { length (years) }\end{array}$ \\
\hline Hornslandet & HORN & 61.73 & 17.44 & 20 & $18 / 27$ & $1742-2017$ & 155 \\
Myrkarby & MYRK & 59.88 & 16.94 & 85 & $31 / 32$ & $1701-2017$ & 232 \\
Ombo öar & OMBO & 58.63 & 14.54 & 120 & $22 / 34$ & $1722-2010$ & 175 \\
Gotland & GOTL & 57.84 & 18.62 & 36 & $21 / 24$ & $1798-2017$ & 161 \\
Fårhagsberget & FAHA & 57.25 & 16.24 & 60 & $19 / 27$ & $1731-2017$ & 178 \\
\hline
\end{tabular}


Peters 1981). This detrending/standardization option preserves annual to decadal variability in the time-series, while eliminating longer-term frequency variations caused for example by the biological age trend or most of the potential heartwood/sapwood color changes (see Fig. 3). Site- and parameter-level chronologies were produced by averaging the dimensionless indices, and truncating the series where sample replication dropped below 5 series. A total of 30 chronologies of 6 different tree-ring parameters (including TRW, earlywood width (EW), latewood width (LW), EWBI, $\mathrm{MXBI}$, and $\Delta \mathrm{BI}$ ) from 5 sites were included in the new dataset (Table 1).

\subsection{Data analysis}

We calculated the Rbar (Wigley et al. 1984) and first-order autocorrelation (AR1) statistics on a site-by-site basis for individual tree-ring chronologies. The former statistic, computed as the average pair-wise correlation between individual detrended series, provides a measure of the strength of the common chronology signal. A principal component analysis (PCA) was performed on all chronologies over their common period (1798-2010) to evaluate common patterns of variability through time within the full network of chronologies. Additionally, PCA was performed separately on a parameter-level to summarize the regional common variability of each individual wood component. Time series of PCA scores of the first two principal components (PC1 and PC2) were retained for climate response analysis. Pearson correlation coefficients were computed to examine the relationship between the time series of the PCA scores and the monthly climate variables. The climate records included gridded monthly mean temperature and total precipitation data from the $0.5^{\circ}$ by $0.5^{\circ}$ gridded CRU TS 4.03 product (Harris et al. 2014), covering the period 1901-2018 and averaged over the region bounded by the latitude/longitude coordinates $57-62^{\circ} \mathrm{N} / 14-19^{\circ} \mathrm{E}$ (Fig. 1). Additionally, climate responses of individual site-chronologies were analyzed using temperature and precipitation records from the CRU TS 4.03 grid-cell closest to each sample site (climate correlation for each individual site and parameter are provided in the supplement, Fig. S1). All climate data series were subjected to the same 67-year spline detrending as the tree-ring data to approximate the spectral properties of the predictor data. This was done to minimize bias in the correlation coefficients from potential multi-decadal and longer-term trends in the climate data, which have already been removed from the tree-ring data.

Calibration/verification experiments of the $\mathrm{PC}$ composites against the optimal season identified by the climate response analysis were conducted using simple linear ordinary least squares regression and an implementation of the split period (1901-1955 and 1956-2010 periods) calibration/verification approach. The test results were evaluated using squared Pearson correlation. Because we place the focus of our analysis on the higher frequencies, the standard reconstruction validation metrics Reduction of Error (RE) and Coefficient of Efficiency (CE) (Hanna 2007) are left without their normal evaluation efficacy. However, we still provide these statistics for reference in the supporting material (Table S2).

The long (1756-2018) quality-checked and homogenized instrumental climate records from the Stockholm meteorological station (Moberg and Bergström 1997; Moberg et al. 2002) were retained for further validation of the calibrated climate signal within the chronology network. Historical data of sea level pressure (SLP) was used as a surrogate for precipitation, since homogenized long-term ( $>150$ years) precipitation data are, as far as we know, not available from the region. The temporal stability of the tree-ring signal was assessed with running 31- and 51-year correlations between the PC composite chronologies and the Stockholm record in addition to the CRU TS 4.03 record used for calibration.

\section{Results}

\subsection{Chronology signals}

The median Rbar, based on five sites, is highest for the MXBI parameter (0.43), closely followed by the $\Delta$ BI parameter (0.42) (Fig. 2). Note, however, the large between-site spread for these two parameters, with Rbar coefficients ranging c. 0.27 to 0.52 . The ring width, earlywood and latewood width parameters, conversely, tend to have a smaller range but lower median Rbar values at just below 0.4. EWBI has the weakest common signal with a median Rbar of 0.18. Significant first-order autocorrelations are only observed for ring width (median AR1 =0.33) and earlywood width (0.29). For comparison purposes, we note that warm-season precipitation exhibits no significant persistence at interannual timescales (AR1 $=-0.14$ when filtered with a 67-year spline) (Fig. 2). The low and non-significant AR1 structure of LW width and the BI components (median AR1 $=0.04-0.12$ ) are more consistent with instrumental climate target data than that of full ring-width and EW width.

Average Pearson's correlation coefficients between all chronology pairs are provided in Table 2, where all parameters, except EWBI, correlate significantly $(p<0.01)$ and positively with each other $(r=0.5-0.98$ over the $1798-2010$ period). In contrast, EWBI is negatively and mostly weakly correlated to ring width, EW width, MXBI and $\Delta \mathrm{BI}$. Figure 3 shows the non-detrended average BI chronologies. The EWBI parameter has less variability than the MXBI parameter, yet both parameters display trends that are in the same order of magnitude. The EWBI measurements will thus have less impact on the derived $\Delta \mathrm{BI}$ parameter 


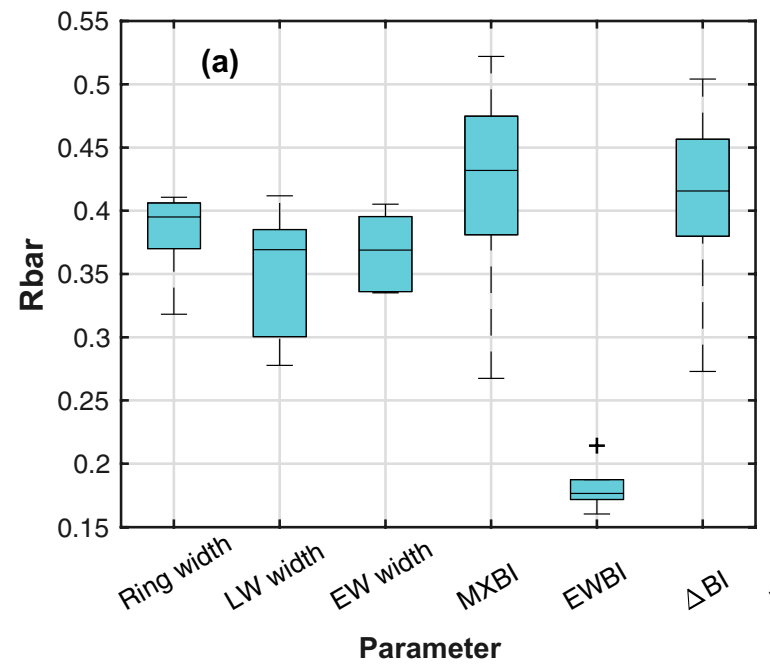

Fig. 2 Boxplot summary of the a Rbar statistic and b first-order autocorrelation (AR1) for each tree-ring parameter. The AR1 coefficients are computed over the 1901-2010 modern interval. Also shown is the

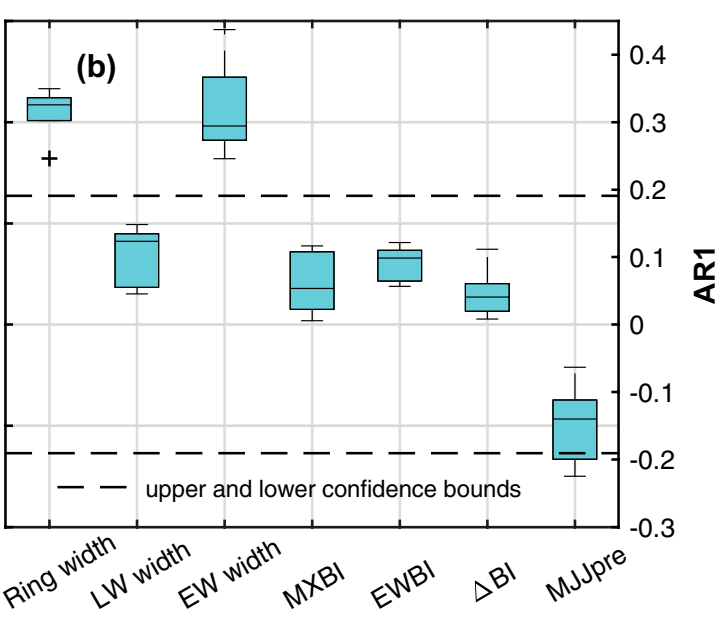

AR1 of the high-pass filtered warm season precipitation (MJJ pre). For definition of abbreviations, see Sect. 2.1
Table 2 Chronology correlation matrix over the common 1798-2010 period

\begin{tabular}{lrrrrr}
\hline & \multicolumn{1}{c}{ Ring width } & LW width & EW width & MXBI & EWBI \\
\hline Ring width & & & & & \\
LW width & $0.80 \pm 0.06$ & & & & \\
EW width & $0.96 \pm 0.01$ & $0.60 \pm 0.06$ & & & \\
MXBI & $0.71 \pm 0.05$ & $0.81 \pm 0.04$ & $0.57 \pm 0.06$ & & \\
EWBI & $-0.25 \pm 0.10$ & $0.07 \pm 0.06$ & $-0.37 \pm 0.08$ & $0.03 \pm 0.06$ & \\
$\Delta$ BI & $0.76 \pm 0.04$ & $0.74 \pm 0.06$ & $0.67 \pm 0.06$ & $0.94 \pm 0.03$ & $-0.32 \pm-0.12$ \\
\hline
\end{tabular}

Correlations are computed separately for each site. The table provides the average correlation across the network and its standard deviation than MXBI, explaining why the correlations between the $\Delta \mathrm{BI}$ parameter and $\mathrm{MXBI}$ are much stronger and less variable $(r=0.90-0.96)$ than the ones between $\Delta \mathrm{BI}$ and EWBI $(r=-0.50$ to -0.17$)$.

To further examine the relationships between the various tree-ring parameters, a PCA was performed on all chronologies over their common period (1798-2010). The first two modes of PCA were analyzed as they represent the major variance in the network, explaining $36.6 \%$ and $13.2 \%$ of the total variability, respectively. Figure 4 gives the PCA biplot (Gabriel 1972). All ring width parameters and MXBI load positively and more or less equally strongly on the first component. However, the LW width and BI components partially separates from the ring width and EW width cluster, and the two cohorts appear in separate quadrants in the PCA biplot. Moreover, ordination of the two components shows a complete separation of EWBI from the rest of the chronologies, with the former having negligible influences on PC1 yet strong and positive loadings on PC2. Ring width and EW width share a negative loading on this axis and are thus negatively correlated with EWBI, as indicated by the $\sim 130^{\circ}$ angle between respective vector cohort. These results are indicative of a pronounced common signal, but also suggest the presence of distinct triple-signal patterns in the dataset. A climate sensitivity analysis was conducted to disentangle this signal structure and further explore the inter-site and inter-parameter consistency of variability (see Sect. 3.2).

\subsection{Climate signals}

Pearson correlations between monthly climate variables and first principal component scores (PC1) of each treering parameter in the full network are summarized in Fig. 5. The leading PC for each parameter accounts for $51-58 \%$ of the total variance, and approximately $37 \%$ when all sites and parameters are combined (Fig. 5), The climate correlation results for individual site chronologies can be found in the supplement (Fig. S1). No significant correlations were obtained for any of the PC2 scores (result not presented). 


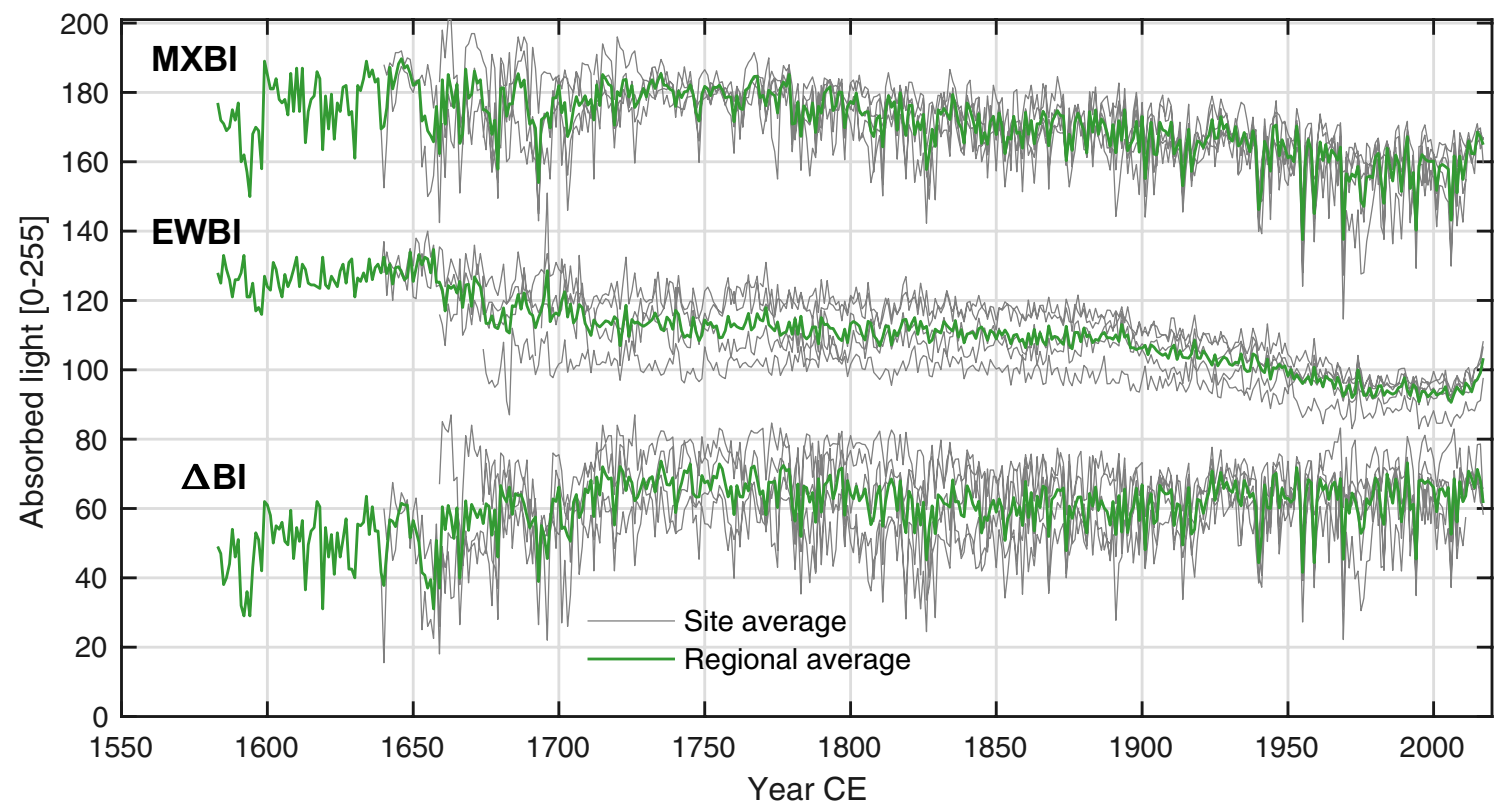

Fig. 3 Raw non-detrended time series of absorbed blue light in the latewood (MXBI) and earlywood (EWBI) portions of the tree rings, and the derived $\Delta \mathrm{BI}$ parameter. Site average (grey lines) and network average (green line) are shown

Fig. 4 Biplot of the first two principal components of the PCA performed over the common 1798-2010 period on the multi-parameter collection from the five sites in Sweden. Identified parameter cohorts are highlighted in green. The color of the vectors corresponds to the different parameters (green lines-EWBI; blue-MXBI; pink-LW width; red-TRW; black-EW width). The first two components together represent nearly $50 \%$ of the total variation

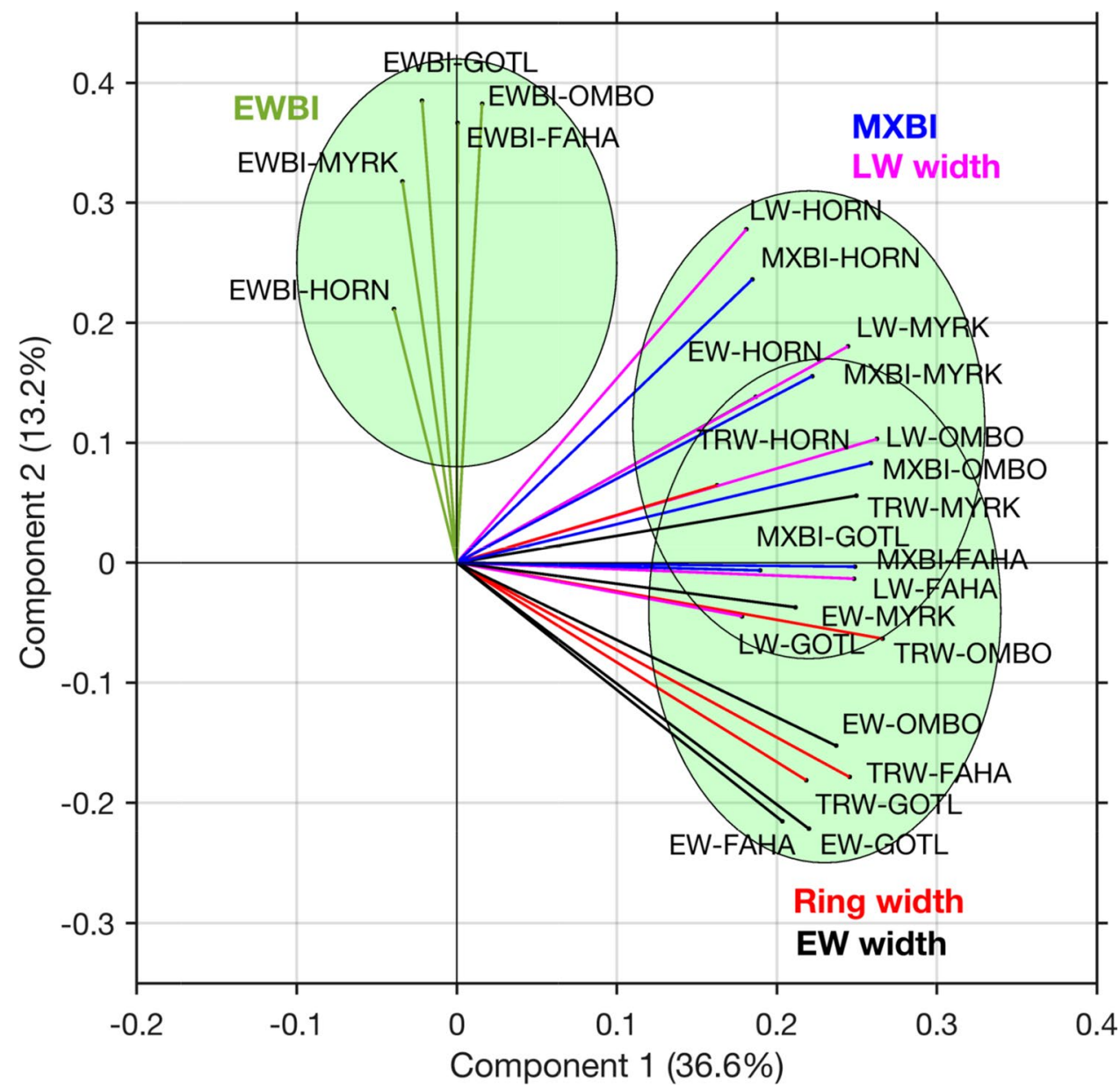


(a) PRECIPITATION
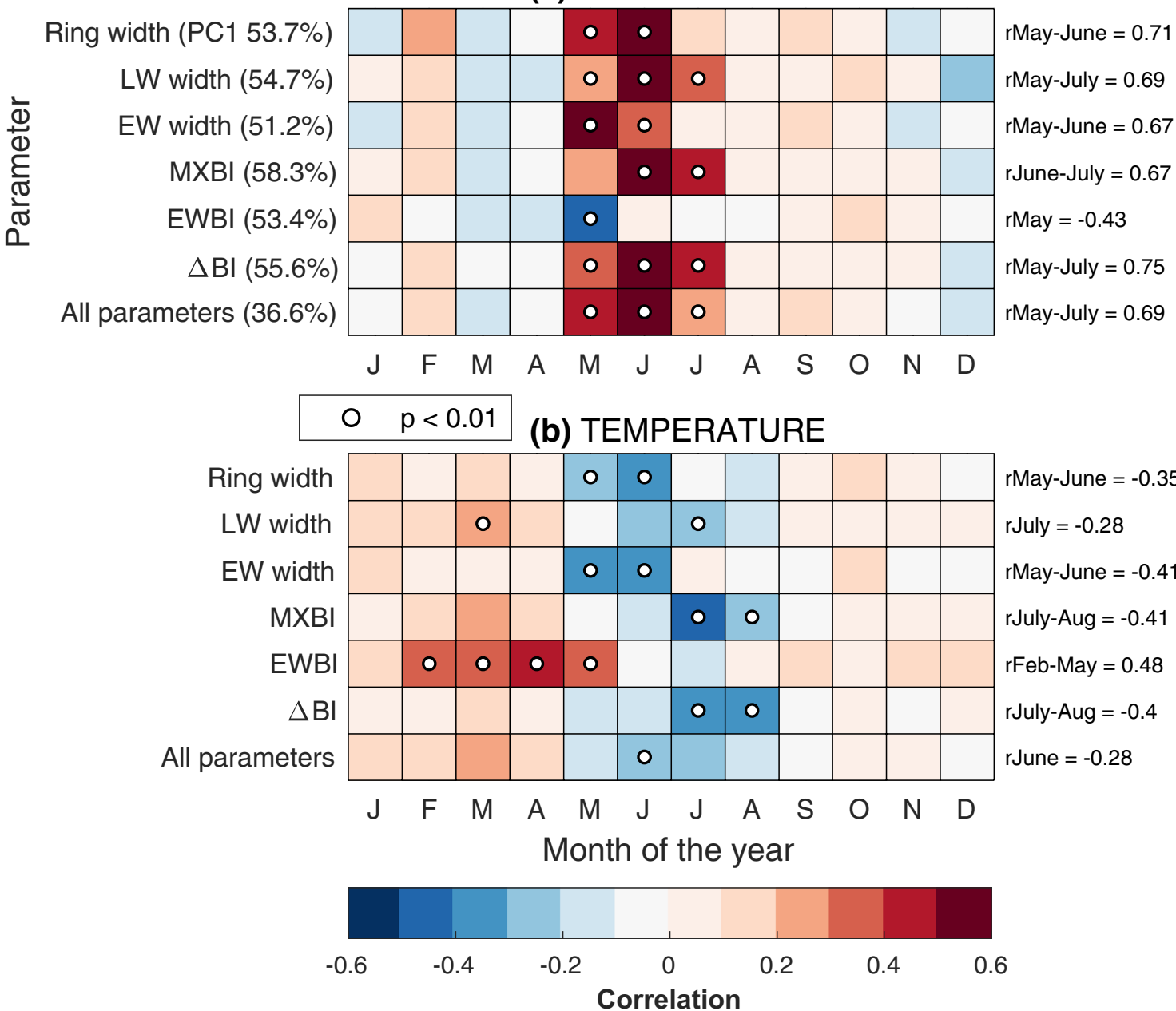

Fig. 5 Simple linear correlations with CRU TS 3.2 monthly a precipitation and $\mathbf{b}$ temperature and the PC1 scores for each tree-ring parameter. Correlations are computed over the 1901-2010 interval using regional $\left(57-62^{\circ} \mathrm{N}\right.$ and $\left.14-19^{\circ} \mathrm{E}\right)$, high-pass filtered, CRU

The correlations with both temperature and precipitation reveal consistent network-wide patterns, with minimal geographical differences over the study domain. The imprint of climate is clearly dominated by a moisture signal, which is evident through a strong relationship with precipitation in one or several months between May and July (Fig. 5). Notably, the different parameters respond to temporally consecutive, albeit overlapping, time windows within the growing season, in line with the successive formation and growth of the different tree-ring components. All parameters, except EWBI, display positive correlations with summer precipitation. The ring width and EW width are sensitive to early summer precipitation (May-June $r=0.67$ and 0.71 for EW width and ring width $\mathrm{PC} 1$, respectively), while correlations between precipitation and LW width and MXBI are generally stronger towards mid-summer (June-July $r=0.67$ for
TS 3.2 averages. The numbers in the parenthesis denote the amount of explained variation by the first PC component. Coefficients in the right of the plot are correlations with seasonally averaged climate variables

MXBI PC1 and May-July $r=0.69$ for LW width PC1). The $\Delta \mathrm{BI}$ displays, in general, an extended seasonal response window of up to three months, from May through July, with a slightly higher correlation (MJJ, $r=0.75$ for $\Delta \mathrm{BI} \mathrm{PC} 1$ ).

Correlations with temperature (Fig. 5b) are weaker and less stable within the network, and mirror in most cases the correlations with precipitation (Fig. 5a). Most parameters, except EWBI, are negatively correlated $(r \sim-0.25$ for PC1) with temperatures in one or several months in the May-August window, suggesting a moisture limitation caused by increased temperatures. Notably, stronger negative correlations are obtained when using monthly maximum temperatures rather than monthly average temperatures (results not shown). Moreover, tendencies toward a weakened warm-season thermal response are found with an increasing latitude of the sites (Fig. S1). These findings 
jointly reinforce the inference about water availabilitydrought being the main limiting factor for tree-growth in these high-latitude cool and well-drained environments. Except for EWBI, all parameters show weak positive lagged responses with prior years' September rainfall (parameter PC1 mean $r \sim 0.25$ ). No significant lagged correlations were found with temperature in the prior year. The correlations of EWBI with climate variables stand out markedly from all other parameters. It displays a broad positive late winter- through- early summer temperature sensitivity (February-May $r=0.48$ for PC1), and a seasonally narrow, yet geographically consistent, negative early summer (May) precipitation signal $(r=-0.43$ for $\mathrm{PC} 1)$.

We compared the spatial extent of the precipitation signals expressed by BI and by ring-width, by computing spatial correlation fields between chronologies and gridded CRU TS 4.03 data (Fig. 6). The analysis was restricted to the regional $\triangle \mathrm{BI} \mathrm{PC} 1$ composite chronology, because it showed the strongest precipitation signal amongst the BI-based parameters (Fig. 5). The results for $\Delta \mathrm{BI}$ reveal broad and significant $(p<0.05)$ correlations with May-July

(a) PC1 $\triangle \mathrm{BI}$ vs. MJJ pr

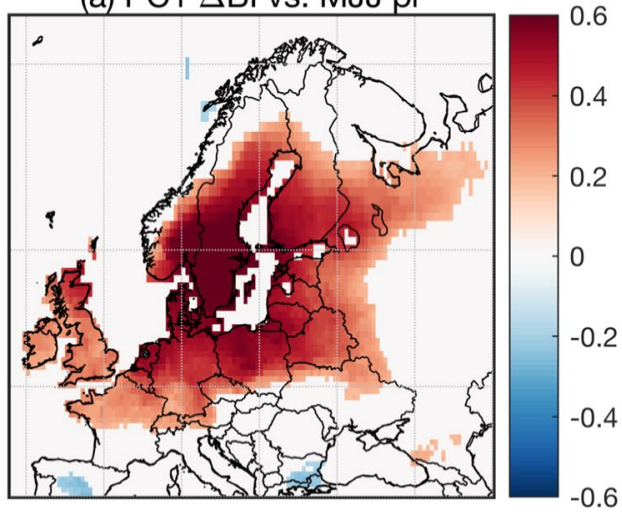

(c) Correlation difference

[PC1 $\Delta \mathrm{BI}$ vs. MJJ pr - PC1 TRW vs. MJJ pr]

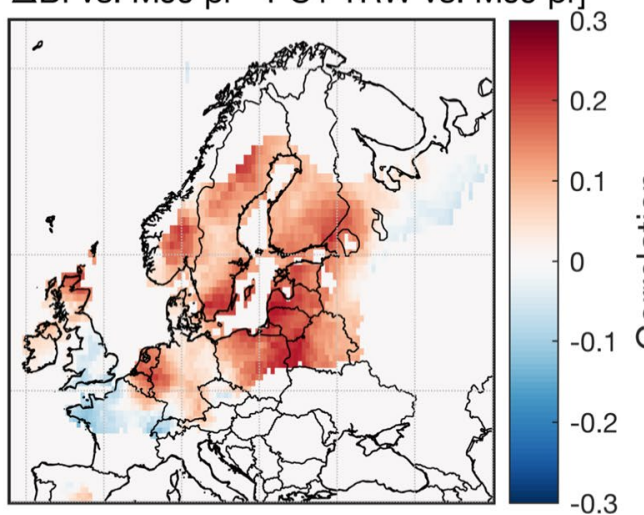

Fig. 6 Field correlation between selected PC1 composite chronologies and gridded meteorological data from the CRU TS 4.03 product over the 1901-2010 period. a $\Delta \mathrm{BI}$ and b ring-width (TRW) versus precipitation spatially (Fig. 6a), with significant correlations present over much of south-central Fennoscandia, central Europe and the British Isles in the 1901-2010 period. Particularly high correlations $(r>0.75)$ are, unsurprisingly, observed close to the sampling locations. Although the spatial response of the ring-width $\mathrm{PC} 1$ composite to MJJ precipitation is confined to roughly the same domain (Fig. 6b), correlations are substantially weaker ( $r$-value differences as high as $\sim 0.3$ ) (Fig. 6c). We also assessed the spatial extent of the late winter to early summer temperature signal in the regional EWBI composite (Fig. 6d). We found it to be broad and statistically significant, with field correlation values of $r>0.4$ over most of Fennoscandia.

\subsection{Time stability of the climate response}

The temporal stability of the chronologies' sensitivity to monthly climate was explored by means of moving window correlation analysis. Results for ring width, $\triangle \mathrm{BI}$ and EWBI against the CRU TS 4.03 product (using a 31-year moving correlation window) are shown in Fig. 7, and against longer (b) PC1 TRW vs. MJJ pr

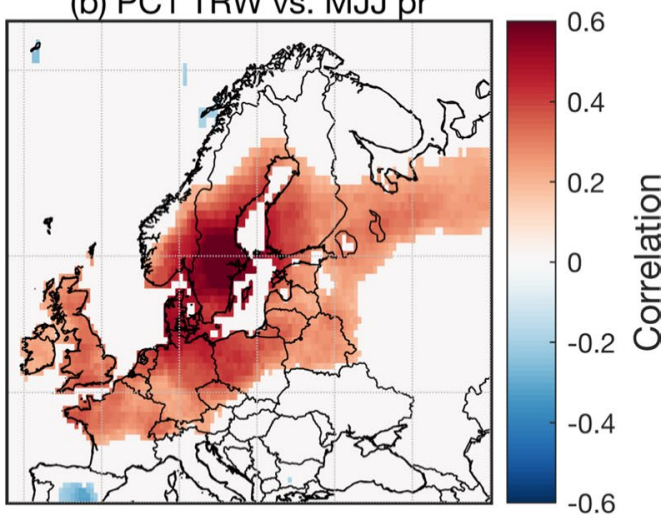

(d) PC1 Blew vs. FMAM tmp

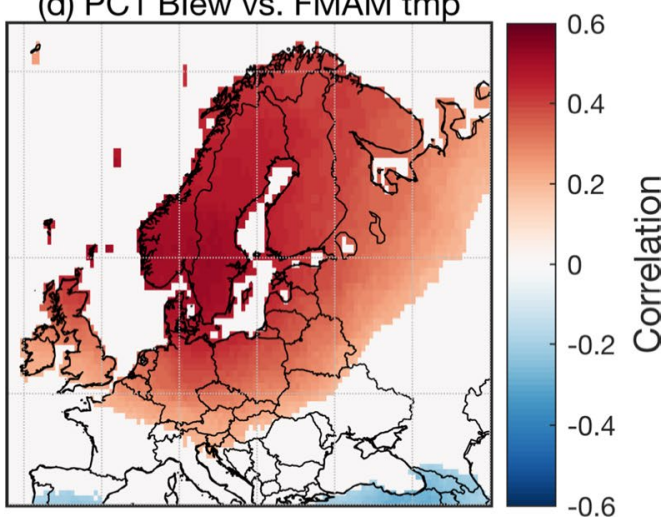

May-July precipitation, $\mathbf{c}$ the difference between the correlation fields shown in plots (b) and (a), d EWBI versus February-May temperature. Correlations are reported in color if significant $(p<0.05)$ 

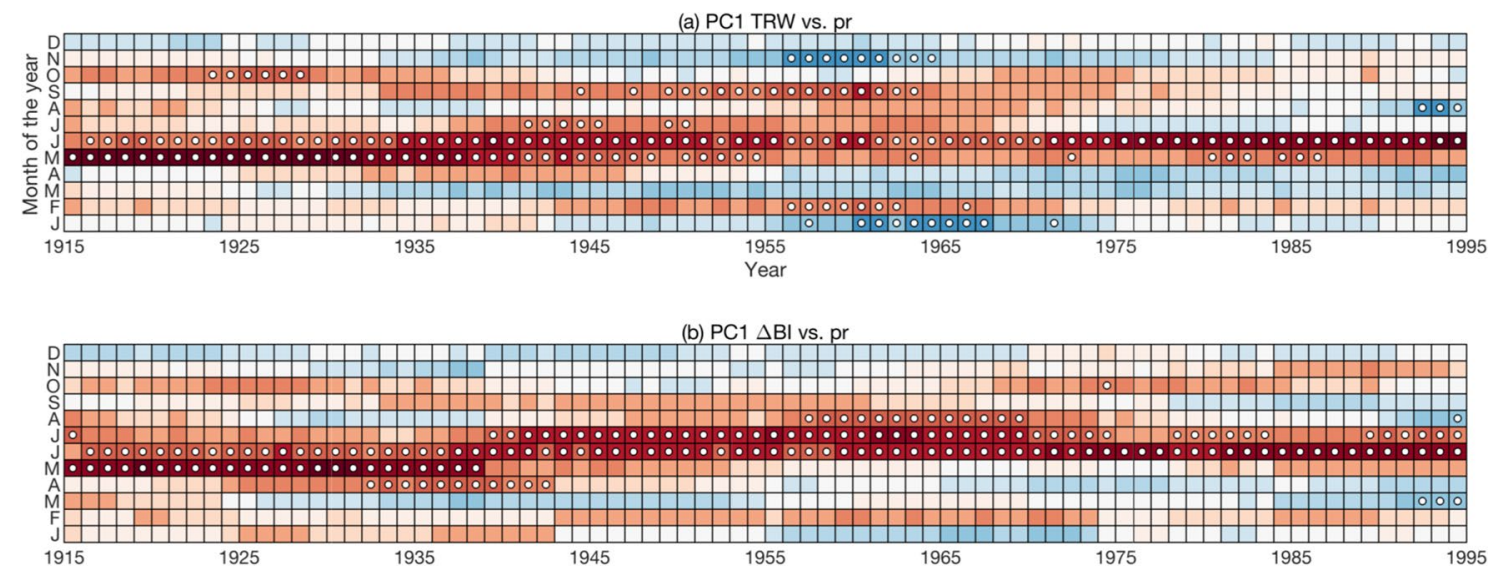

(c) PC1 EWBI vs. pr

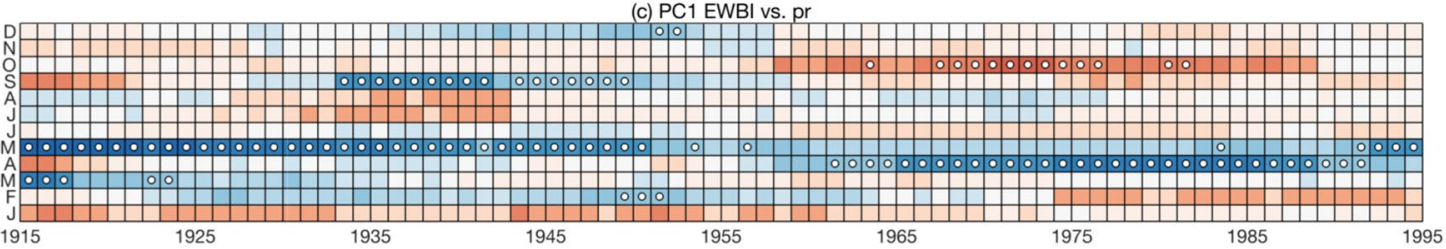

(d) PC1 EWBI vs. tmp

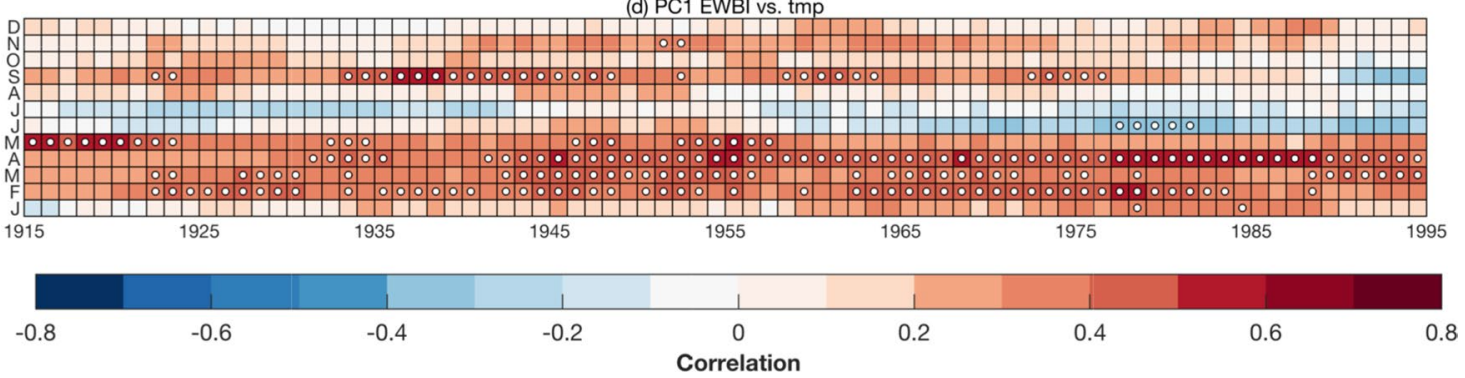

Fig. 7 Moving 31-year window correlation over the 1901-2010 period between selected PC1 composite chronologies and gridded meteorological data from the CRU TS 4.03 product. a Ring-width (TRW) and b $\Delta \mathrm{BI}$ versus precipitation, EWBI versus $\mathbf{c}$ precipita- tion and $\mathbf{d}$ temperature. Precipitation and temperature data have been high-pass filtered and averaged over the region bounded by the latitude/longitude coordinates $57-62^{\circ} \mathrm{N} / 14-19^{\circ} \mathrm{E}$

early summer temperature signal of EWBI in the first half of the twentieth century (Fig. 7d). Moving window correlations against Stockholm historical meteorological data over the 1798-2010 period show that all parameters have some degree of signal instability prior to the twentieth century, yet that $\Delta \mathrm{BI}$ is the variable that displays the most stationary response over time (Fig. S3). The EWBI parameter largely loses its sensitivity to May precipitation (not shown), yet remains sensitive to late winter through early summer temperatures throughout the 1798-2010 interval (Fig. S3c).

\subsection{Climate reconstruction potential}

Based on the climate sensitivity analysis (Sect. 3.2) and the tests of the uniformitarian principle (Sect. 3.3), we now evaluate the potential of the new tree-ring parameters in also observe a slight weakening in the late winter through 
reconstructions of regionally-averaged warm-season precipitation and late-winter/early-summer temperatures in the high-frequency portion of the variability. We restrict the analysis to two variables: $\Delta \mathrm{BI}$ and EWBI. $\Delta \mathrm{BI}$ is selected because it contains the strongest, seasonally most broad, and temporally stable response to summer precipitation; EWBI because of its sensitivity to winter/spring temperatures-a rarely reconstructed climate variable and therefore particularly interesting from a paleoclimate perspective. For comparative purposes we also include ring width, as this is the tree-ring parameter that has most frequently been used as a predictor in hydroclimate reconstructions for Fennoscandia (Helama et al. 2009; Seftigen et al. 2013, 2017). The calibration experiments are performed separately for $\Delta \mathrm{BI}$ and ringwidth PC1 composites, due to the high collinearity among the two parameters.

The calibration/validation results for the different reconstruction are summarized in Table 3 . We find that model calibration using $\Delta \mathrm{BI}$ clearly provides the best estimate of warm-season (May-July) precipitation. The reconstruction model has consistent predictive power in the early (1901-1955) and late (1956-2010) calibration/verification subintervals, with model explained variance $\left(R^{2}\right)$ ranging from 54 to $58 \%$. When calibrated over the entire 1901-2010 period, the regression model is able to account for $56 \%$ of the fractional variance in the instrumental precipitation data. In comparison, calibration of the tree ring width PC1 composite with May-June precipitation yield more unstable calibration/verification metrics (Table 3). Variance explained with the instrumental data peaks at $54 \%$ in the early part of the twentieth century, but drops to just $24 \%$ in the latter half of the century. The full interval ring width model captures just $37 \%$ of the variability in the observed MJJ precipitation, nearly 20 percentage points less than the $\Delta \mathrm{BI}$ reconstruction. In contrast, statistically more robust results are found when calibrating the PC1 ring width composite with the shorter yet for this parameter optimal May-June target season, with $R^{2}$-values of $0.51-0.55$. For EWBI, calibration to February-May temperatures yielded more modest test statistics $\left(R^{2}=0.20-0.26\right)$ than the calibration experiments with $\Delta \mathrm{BI}$ and ring width, yet with encouragingly stable reconstruction fidelity in the two calibration/verification subperiods.

The final parameter-based reconstructions are shown in Fig. 8. The $\Delta \mathrm{BI}$ derived warm-season rainfall estimates are in close agreement with the CRU TS 4.03 observational precipitation data; however, we note that some of the dry extremes are overestimated in the reconstruction (potentially a measurement-related bias, see Fig. 10 and Sect. 4). The $\Delta \mathrm{BI}$ and EWBI rainfall and temperature reconstructions are further compared with early data from the Stockholm meteorological station (Fig. 9), The long Stockholm records are independent from the CRU TS 4.03 dataset in the pre-1900 period, and thus provide additional validation of the calibrated signals. The correlations between the MJJ precipitation reconstruction and the fully independent historical SLP observations outside the calibration interval (1798-1900) is -0.48 , and over the entire common interval (1798-2010) -0.47 ( $p<0.001$ in both cases), giving confidence that the reconstruction is temporally stable and reliable. The EWBI temperature reconstruction correlates at $0.41(p<0.001)$ with Stockholm temperatures over the full period of overlap, and $0.34(p<0.001)$ in the period withheld from calibration (1798-1900).

\section{Discussion}

The current study provides the first comparison of the Blue Intensity (BI) measurements with ring width measurements from Scots pine growing in cool and humid albeit well-drained environments in Sweden. We show that all of these wood components are clearly and strongly correlated to precipitation during the warm-season, and that they are capable of providing fundamental information to advance our understanding of past hydroclimate variability. As a cold and relatively humid northern region, it risks a priori being overlooked in dendroclimatic studies of past droughts due to its rather benign hydroclimate regime (Ljungqvist et al. 2020 b). Out of six investigated parameters, the $\Delta \mathrm{BI}$ component appeared to capture the strongest precipitation signal.
Table 3 Calibration/validation results for reconstructions based on ring width (TRW), $\Delta \mathrm{BI}$ and EWBI, respectively

\begin{tabular}{|c|c|c|c|c|c|c|c|}
\hline \multirow[b]{2}{*}{ Tree-ring parameter } & \multirow[b]{2}{*}{ Climate target } & \multicolumn{2}{|c|}{$\begin{array}{l}1901-1955 \text { cali- } \\
\text { bration }\end{array}$} & \multicolumn{2}{|c|}{$\begin{array}{l}\text { 1956-2010 verifi- } \\
\text { cation }\end{array}$} & \multicolumn{2}{|c|}{$\begin{array}{l}\text { Full 1901- } \\
2010 \text { calibra- } \\
\text { tion }\end{array}$} \\
\hline & & $r$ & $R^{2}$ & $r$ & $R^{2}$ & $r$ & $R^{2}$ \\
\hline PC1 TRW & MJ precipitation & 0.74 & 0.55 & 0.69 & 0.47 & 0.71 & 0.51 \\
\hline PC1 TRW & MJJ precipitation & 0.73 & 0.54 & 0.49 & 0.24 & 0.61 & 0.37 \\
\hline $\mathrm{PC} 1 \Delta \mathrm{BI}$ & MJJ precipitation & 0.76 & 0.58 & 0.73 & 0.54 & 0.75 & 0.56 \\
\hline PC1 EWBI & FMAM temperature & 0.45 & 0.20 & 0.51 & 0.26 & 0.48 & 0.23 \\
\hline
\end{tabular}

Experiments were performed over the 1901-1955, 1956-2010 and the full 1901-2010 periods. We used high-pass filtered precipitation and temperature data from the CRU TS 4.03 product, averaged over the region bounded by the latitude/longitude coordinates $57-62^{\circ} \mathrm{N} / 14-19^{\circ} \mathrm{E}$ as a predictand 
Fig. 8 Scaled PC1 composite reconstructions and their target CRU TS 4.03 instrumental data. a Ring width- and $\mathbf{b} \Delta \mathrm{BI}$-based MJJ precipitation reconstructions, and comparison between these two reconstructions. d $\Delta$ BI-based February-May temperature reconstruction. Correlations between time-series are provided in the bottom of each plot. Note that data have been high-pass filtered and normalized to $z$-scores over the entire record length
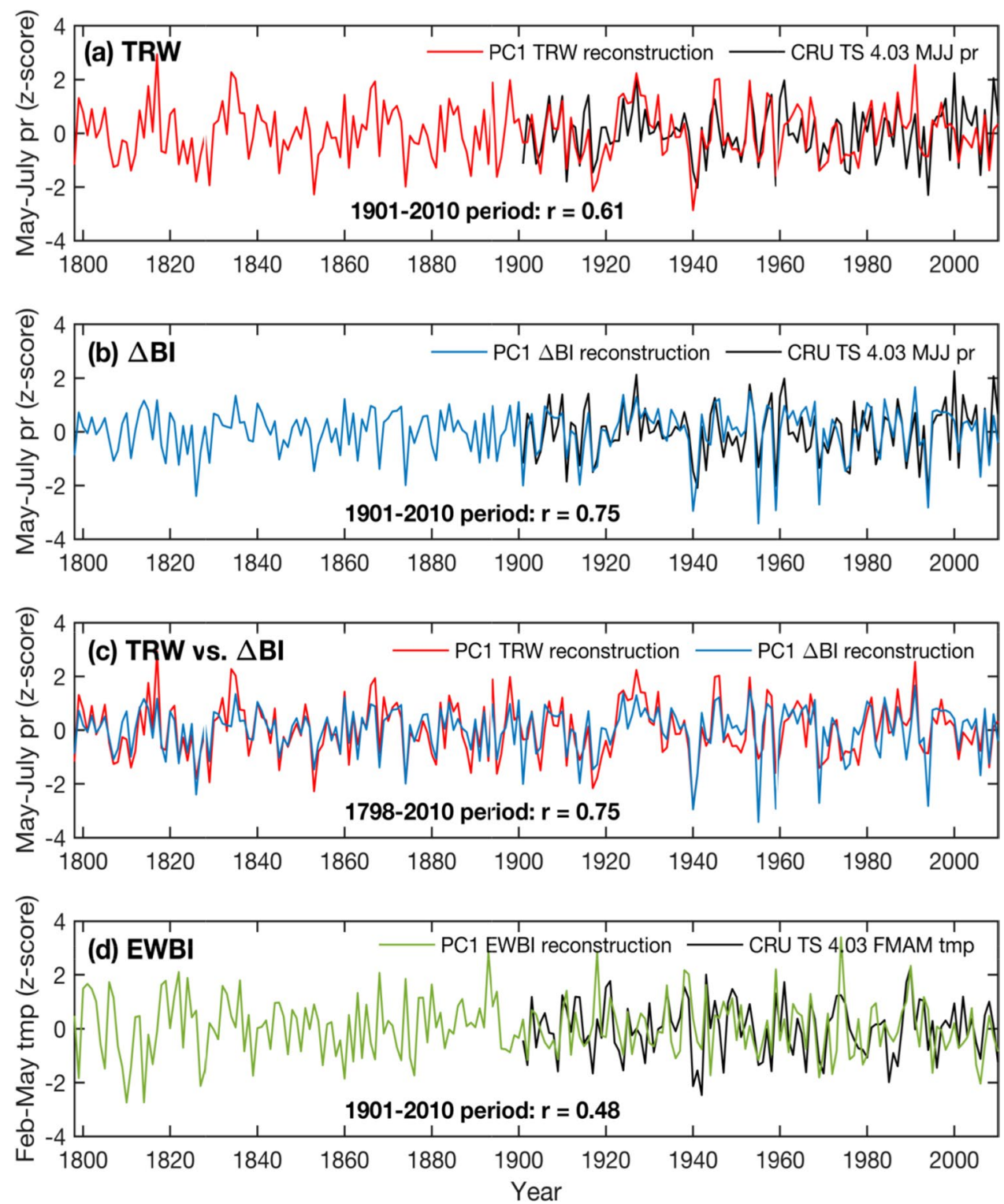

This permitted a cross-validated precipitation reconstruction capable of explaining well over half of regional-scale warm-season precipitation variance. We show that the $\Delta \mathrm{BI}$ reconstruction not only improve the predictive skill of the ring width based model, with nearly a 20 percentage points increase in explained variance, but also allows for a broader seasonal window to be reconstructed, which is particularly important for the temporal stability of reconstructions (Frank et al. 2007).

Precipitation deficit and droughts are the main restriction of tree functioning, wood formation and growth in the cold and well-drained environments studied here. We found a strong link between low density of the latewood (i.e. a lower MXBI value) and dry, as well as hot, summer conditions. These results are in stark contrast to prior MXD/MXBI studies in the cooler and mountainous parts of Fennoscandia further north, where summer temperatures is identified as the main driver of latewood density (Esper et al. 2012; Fuentes et al. 2018; Linderholm et al. 2010,2015; Melvin et al. 2013), and where precipitation clearly plays a subordinate role (Seftigen et al. 2015b). While wood density in conifers is a function of tracheid dimensions (cell size and wall thickness) (Vaganov et al. 2006), the effect of cell size on wood density tends to dominate in the earlywood, whereas the density of the latewood component is generally more closely associated with variation in cell-wall thickness (Björklund et al. 2017; Yasue et al. 2000). Following this postulation, it is likely that the climate response pattern of latewood density revealed by our data is related to stomatal closure to prevent hydraulic failure thus reduced carbon assimilation rates in drier years (McDowell et al. 2008), resulting in resource deficiency in the wall thickening and 

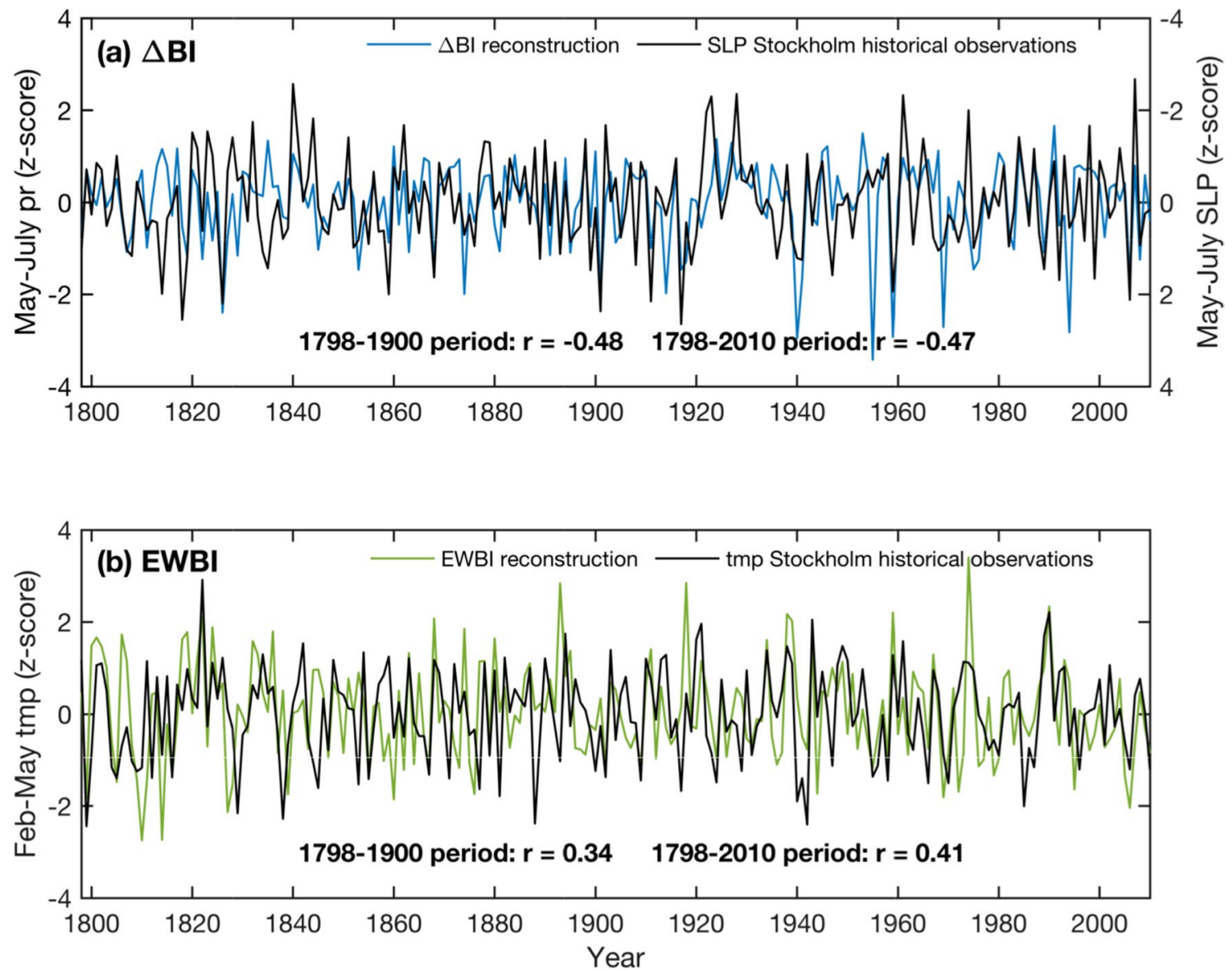

Fig. 9 Time-series of the a $\Delta \mathrm{BI}$-based MJJ precipitation (pr) reconstruction and historical meteorological records of sea-level pressure (SLP); b EWBI-based FMAM temperature reconstruction and historical records of temperature (tmp) from the Stockholm meteorological station. Note that SLP explains less than $40 \%$ of the variability in

summer precipitation in the region (Fig. S3). Data have been highpass filtered and normalized to $z$-scores over the entire record length. Correlations between time-series are provided in the bottom of each plot
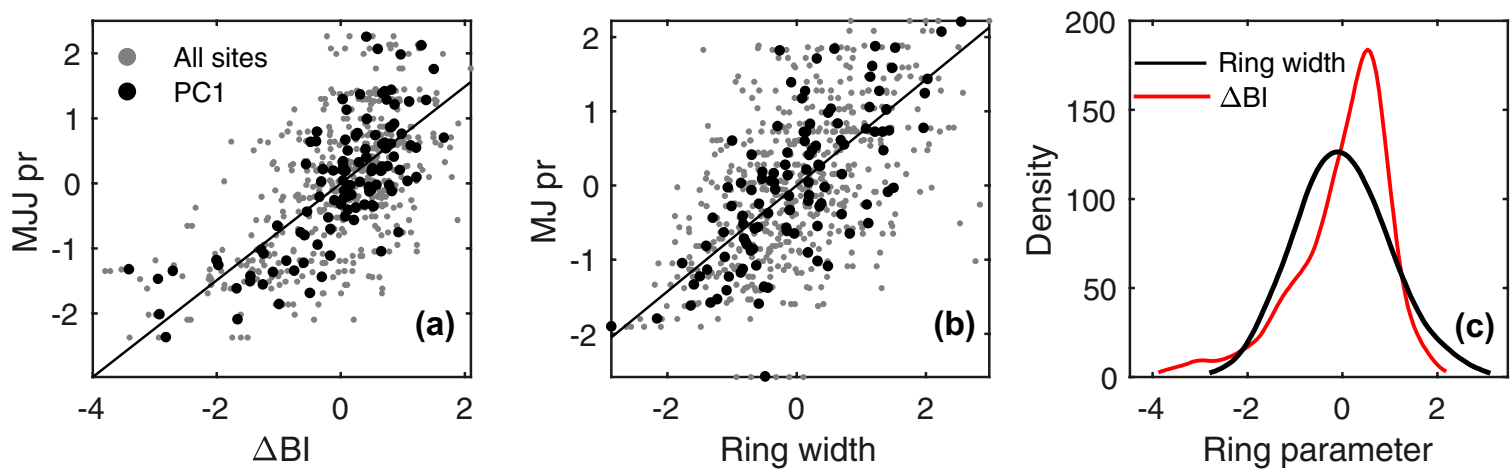

Fig. 10 Scatter-plot comparisons between warm-season CRU TS 4.03 precipitation and a $\Delta \mathrm{BI}$ and $\mathbf{b}$ ring width. Note that the regionally-averaged precipitation is normally distributed. $\mathbf{c}$ Kernel probability density functions of $z$-scored ring-width and $\Delta \mathrm{BI}$ individual-site chronologies

lignification phase of latewood tracheids. This may explain why denser latewood predominates in years of increased latewood growth and favorable climate conditions. Moreover, in line with prior studies in warm (Camarero et al.
2014; Cleaveland 1986) and cold (Camarero et al. 2017) xeric environments, we found that wet conditions early in the growing season tend to promote earlywood width growth, and to reduce earlywood density. The precipitation-density 
coupling is likely connected to a drought-driven reduction in tracheid lumen size, and related decreases in hydraulic conductivity, radial growth and wood production (see Camarero et al. 2017 and references therein; Camarero et al. 2014). Notably, we also see a thermal dependence of the earlywood density, specifically that the formation of denser earlywood is correlated with warm late winter- through- early summer temperature (previously also observed in tropical conifers, Buckley et al. (2018)). The thermal control could be linked to earlier cambial resumption and prolonged duration and rate of metabolic processes (Rossi et al. 2006), leading to enhanced carbohydrate synthesis, increased lignification and cell wall synthesis of earlywood tracheids in response to a warm early growing season. Here, we can only hypothesize about these mechanisms, but continued efforts to shed more light on these issues would benefit from including measurements of the anatomical components of density (sensu Björklund et al. 2017).

Our results demonstrate the considerable potential of using BI to complement the currently available ring-width based hydroclimate reconstructions for the Fennoscandian region, and possibly also other regions with similar climate regimes. The $\Delta \mathrm{BI}$-parameter offers several advantages as a proxy. First of all, our data suggests a stronger common signal strength of $\Delta \mathrm{BI}$ compared to ring width, meaning that fewer trees are required to provide a representative sample for calibration with climate data. Whether this holds true at longer (multi-decadal to multi-centennial) time-scales given the potential limitation of BI parameters at these frequencies (Björklund et al. 2014; Buckley et al. 2018; Rydval et al. 2014) remains, however, to be evaluated. We note also that a weaker common signal of the $\Delta \mathrm{BI}$ parameter is not uncommon to find in other tree species and environments (e.g., Blake et al. 2020), and stress that this evaluation always should be exercised on a site-by-site basis. However, the ease and low cost of producing BI data does not pose a severe obstacle for increasing replication unless tree samples are simply not available. Secondly, the first-order autocorrelation of the $\Delta \mathrm{BI}$ parameter is insignificant. That is, the autocorrelation of the $\Delta \mathrm{BI}$ parameter is thus more consistent with the autocorrelation of the target instrumental precipitation data than with ring width. In fact, it has repeatedly been shown that ring width chronologies have strong biological persistence and higher autocorrelation than MXD (Büntgen et al. 2015; Esper et al. 2015; Ljungqvist et al. 2020a). Likewise, ring width dominated proxy collections tend to overestimate the ratio of low- to high-frequency variability in the instrumental records (Ault et al. 2013; Franke et al. 2013; Hartl-Meier et al. 2017).

Importantly, the $\Delta \mathrm{BI}$ based warm-season rainfall reconstruction provides a substantial improvement over previous ring width reconstructions because it not only expands the reconstructed seasonal window, it is also able to explain a larger fraction of the variance of the instrumental record, as well as being less subjected to signal instabilities over time. In fact, a longer optimal target window allows for temporally less variable correlations between the tree ring chronology and the seasonally averaged climate target, as small shifts in seasonality will have a more pronounced implications when the target window is narrow (Frank et al. 2007). Moreover, using MXBI and EWBI and partial-width measurements, rather than ring width alone, can provide information about climate in different portions of the growing season, adding a finer level of detail at an intra-seasonal scale.

There are still many unresolved problems facing the application of BI. There may be trends and variability in these measurements that are not linked to climate, but rather to systematic color changes of the wood material (Björklund et al. 2014; Buckley et al. 2018; Rydval et al. 2014; Wilson et al. 2017), such as the abrupt heartwood/sapwood color transition, fungal staining or oxidation (Björklund et al. 2019). The heartwood/sapwood bias is apparent in the raw un-detrended BI time-series (Fig. 3), seen as an increasingly steep decline around 1900 CE subsequently neutralized around 1960. It arises because each raw measurement of MXBI and EWBI exhibit a more or less negative step in trend when transitioning from heartwood to sapwood, and that most heartwood/sapwood transitions of our sample material dates to between the late nineteenth century and mid-twentieth century. Because the heartwood/sapwood discoloration arguably is similar in the earlywood and latewood, it could be possible to neutralize the color difference by subtracting the EWBI from the MXBI to derive the $\Delta$ BI (Björklund et al. 2014). Nevertheless, with the dynamic detrending implemented in this study, the systematic and non-climate related trends should be neutralized in all parameters, allowing us to identify unbiased climate imprints in the tree-ring data at high frequencies. The discoloration problems would however require more careful scrutiny when attempting to preserve lower-frequency signals in the BI time-series, e.g. at centennial to multi-centennial time-scales. In this context, the $\Delta \mathrm{BI}$ parameter appears even more attractive than has already been shown in the statistical criteria tested in this study.

Additional biases using basic BI techniques include the relatively low measurement resolution (Björklund et al. 2019). The MXBI of climate stressed conifers may in some instances be represented by only a few cells in the radial direction (Vaganov et al. 2006). If the measurement resolution is coarser than the radial extension of the "true" MXD or MXBI area, then these parameters will be deflated and increasingly dependent on the latewood width (see Fig. S4 in the supporting material). If we consider for our material that MXD and ring width have a strong and true relationship, very narrow rings naturally are accompanied by very low MXBI values. A potential measurement bias postulate 
that narrow rings will have even lower MXBI values than expected. This is probably a reason for the observed skewed distribution of the MXBI values in our collection (Fig. 10c), and it may explain the tendencies to a non-linear relationship between MXBI and precipitation (Fig. 10a). Thus, even though our results are very encouraging for hydroclimate reconstructions of the region, there appears to be additional room for improvement using highly resolved techniques such as X-ray densitometry or even quantitative wood anatomy. The advantage using anatomical density of course includes a more in-depth understanding of the derived signals, where climate signals are expected to be more distinct from ring widths, but also, the complete removal of any heartwood sapwood bias (Björklund et al. 2019, 2020).

\section{Conclusions}

In this paper we explore if an improved inference of past hydroclimate can be obtained using Blue Intensity (BI) and partial ring width measurements from a network of cool and drought-prone Pinus sylvestris sites in southern and central Sweden. By comparing the different width- and BI-parameters and their relation with climate, we find great potential of using wood density also in well-drained areas with relatively benign climate. These novel findings provide a significant empirical foundation in the high-latitude Northern Hemisphere, where presently few truly moisturesensitive high-resolution proxy data exist (Linderholm et al. 2018). Moreover, the results are of particular importance for Fennoscandia, where the available long moisture-sensitive proxy records possess an unrealized potential using only ring width (e.g., see the tree-ring collection in Cook et al. 2015). We explicitly draw attention to the dendroclimatic potential of $\Delta \mathrm{BI}$-derived reconstruction using our approach, explaining $>55 \%$ of the variance in warm season, high-pass filtered, precipitation. This is an improvement of nearly 20 percentage points in explained variance in the predictive skill of the ring width based precipitation reconstruction. Thus, by developing wood densitometric chronologies there is a great potential to produce the most robust tree-ring reconstructions of hydroclimate so far available in the Fennoscandian region.

This research has focused on one species and a fairly limited geographical portion of Fennoscandia. More research is needed to determine if our findings can be generalized to additional conifer species and other high-latitude cool-dry sites. Moreover, we recommend that future work should be focused on increasing the temporal extension of chronologies and to implement more highly resolved measurement techniques to maximize, and to more fully understand the imprinted climate signals, as well as minimize measurement biases.

Acknowledgements We sincerely thank three anonymous referees for valuable critique to an earlier version of the manuscript. Open access funding provided by University of Gothenburg. Funding for this research was primarily provided by FORMAS (Grants No. 201400723 and 2019-01482 to K.S.), the Swedish Research Council (Vetenskapsrådet, Grants No. 2019-05228 to K.S. and 2018-01272 to F.C.L.). J.B acknowledge funding from the Swiss National Science Foundation SNSF (project XELLCLIM no. 200021-182398). F.C.L. conducted most of the work with this article as a Pro Futura Scientia XIII Fellow funded by the Swedish Collegium for Advanced Study through Riksbankens Jubileumsfond. The authors thank Georg von Arx for valuable input and discussions that improved this manuscript. We are also grateful for the assistance provided by Stuart and Monty during the update of the tree-ring data network.

Open Access This article is licensed under a Creative Commons Attribution 4.0 International License, which permits use, sharing, adaptation, distribution and reproduction in any medium or format, as long as you give appropriate credit to the original author(s) and the source, provide a link to the Creative Commons licence, and indicate if changes were made. The images or other third party material in this article are included in the article's Creative Commons licence, unless indicated otherwise in a credit line to the material. If material is not included in the article's Creative Commons licence and your intended use is not permitted by statutory regulation or exceeds the permitted use, you will need to obtain permission directly from the copyright holder. To view a copy of this licence, visit http://creativecommons.org/licenses/by/4.0/.

\section{References}

Ault TR et al (2013) The continuum of hydroclimate variability in Western North America during the Last Millennium. J Clim 26:5863-5878. https://doi.org/10.1175/jcli-d-11-00732.1

Barnett T, Adam J, Lettenmaier D (2005) Potential impacts of a warming climate on water availability in snow-dominated regions. Nature 438:303-309. https://doi.org/10.1038/nature04141

Björklund J, Gunnarson BE, Seftigen K, Esper J, Linderholm HW (2014) Blue intensity and density from northern Fennoscandian tree rings, exploring the potential to improve summer temperature reconstructions with earlywood information. Clim Past 10:877885. https://doi.org/10.5194/cp-10-877-2014

Björklund J et al (2017) Cell size and wall dimensions drive distinct variability of earlywood and latewood density in Northern Hemisphere conifers. New Phytol 216:728-740. https://doi. org/10.1111/nph.14639

Björklund J et al (2019) Scientific merits and analytical challenges of tree-ring densitometry. Rev Geophys 57:1224-1264. https://doi. org/10.1029/2019RG000642

Björklund J, Seftigen K, Fonti P, Nievergelt D, von Arx G (2020) Dendroclimatic potential of dendroanatomy in temperature-sensitive Pinus sylvestris. Dendrochronologia 60:125673. https://doi. org/10.1016/j.dendro.2020.125673

Blake SAP, Palmer JG, Björklund J, Harper JB, Turney CSM (2020) Palaeoclimate potential of New Zealand Manoao colensoi (silver pine) tree rings using Blue-Intensity (BI). Dendrochronologia 60:125664. https://doi.org/10.1016/j.dendro.2020.125664

Buckley BM et al (2018) Blue intensity from a tropical conifer's annual rings for climate reconstruction: an ecophysiological perspective. 
Dendrochronologia 50:10-22. https://doi.org/10.1016/j.dendr o.2018.04.003

Büntgen U et al (2015) Tree-ring amplification of the early nineteenthcentury summer cooling in Central Europe. J Clim 28:5272-5288. https://doi.org/10.1175/JCLI-D-14-00673.1

Camarero JJ, Rozas V, Olano JM, Fernández-Palacios JM (2014) Minimum wood density of Juniperus thuriferais a robust proxy of spring water availability in a continental Mediterranean climate. J Biogeogr 41:1105-1114. https://doi.org/10.1111/jbi.12271

Camarero JJ, Fernández-Pérez L, Kirdyanov AV, Shestakova TA, Knorre AA, Kukarskih VV, Voltas J (2017) Minimum wood density of conifers portrays changes in early season precipitation at dry and cold Eurasian regions. Trees 31:1423-1437. https://doi. org/10.1007/s00468-017-1559-x

Cleaveland MK (1986) climatic response of densitometric properties in semiarid site tree rings. Tree-Ring Bull 46:13-29

Cook ER, Peters K (1981) The smoothing spline: a new approach to standardizing forest interior tree-ring width series for dendroclimatic studies. Tree-Ring Bull 41:45-53

Cook ER, Woodhouse CA, Eakin CM, Meko DM, Stahle DW (2004) Long-term aridity changes in the Western United States. Science 306:1015-1018. https://doi.org/10.1126/science.1102586

Cook ER et al (2015) Old World megadroughts and pluvials during the Common Era. Sci Adv 1:e1500561. https://doi.org/10.1126/ sciadv. 1500561

Cook BI et al (2016) North American megadroughts in the Common Era: reconstructions and simulations WIREs. Clim Change 7:411432. https://doi.org/10.1002/wcc.394

Drobyshev I, Niklasson M, Linderholm HW, Seftigen K, Hickler T, Eggertsson O (2011) Reconstruction of a regional drought index in southern Sweden since AD 1750. Holocene 21:667-679. https ://doi.org/10.1177/0959683610391312

Esper J et al (2012) Orbital forcing of tree-ring data. Nat Clim Change 2:862-866. https://doi.org/10.1038/nclimate1589

Esper J, Schneider L, Smerdon JE, Schöne BR, Büntgen U (2015) Signals and memory in tree-ring width and density data. Dendrochronologia 35:62-70. https://doi.org/10.1016/j.dendro.2015.07.001

Esper J et al (2016) Ranking of tree-ring based temperature reconstructions of the past millennium. Quat Sci Rev 145:134-151. https:// doi.org/10.1016/j.quascirev.2016.05.009

Esper J et al (2018) Large-scale, millennial-length temperature reconstructions from tree-rings. Dendrochronologia 50:81-90. https:// doi.org/10.1016/j.dendro.2018.06.001

Frank D, Büntgen U, Böhm R, Maugeri M, Esper J (2007) Warmer early instrumental measurements versus colder reconstructed temperatures: shooting at a moving target. Quat Sci Rev 26:32983310. https://doi.org/10.1016/j.quascirev.2007.08.002

Franke J, Frank D, Raible CC, Esper J, Brönnimann S (2013) Spectral biases in tree-ring climate proxies. Nat Clim Change 3:360. https ://doi.org/10.1038/nclimate1816

Fuentes $\mathrm{M}$ et al (2018) A 970-year-long summer temperature reconstruction from Rogen, west-central Sweden, based on blue intensity from tree rings. Holocene 28:254-266. https://doi. org/10.1177/0959683617721322

Gabriel KR (1972) Analysis of meteorological data by means of canonical decomposition and biplots. J Appl Meteorol 11:1071-1077. https://doi.org/10.1175/1520-0450(1972)011\%3c1071:AOMDB $\mathrm{M} \% 3 \mathrm{e} 2.0 . \mathrm{CO} ; 2$

Gärtner H, Nievergelt D (2010) The core-microtome: a new tool for surface preparation on cores and time series analysis of varying cell parameters. Dendrochronologia 28:85-92. https://doi. org/10.1016/j.dendro.2009.09.002

Hanna E (2007) Surface temperature reconstructions for the last 2000 years by National Research Council. The National Academies Press, Washington, DC, 2006. xix + 145pp. ISBN 0309102 251, Weather 62:346-346. doi:10.1002/wea.162
Harris I, Jones PD, Osborn TJ, Lister DH (2014) Updated high-resolution grids of monthly climatic observations-the CRU TS3.10 dataset. Int J Climatol 34:623-642. https://doi.org/10.1002/ joc. 3711

Hartl-Meier CTM et al (2017) Temperature covariance in tree ring reconstructions and model simulations over the past millennium. Geophys Res Lett 44:9458-9469. https://doi.org/10.1002/2017G L073239

Helama S, Meirläinen J, Tuomenvirta H (2009) Multicentennial megadrought in northern Europe coincided with a global El NiñoSouthern Oscillation drought pattern during the medieval climate anomaly. Geology 37:175-178. https://doi.org/10.1130/g25329a.1

Holmes RL (1983) Computer-assisted quality control in tree-ring dating and measurement. Tree-Ring Bull 43:69-78

Konter O, Büntgen U, Carrer M, Timonen M, Esper J (2016) Climate signal age effects in boreal tree-rings: lessons to be learned for paleoclimatic reconstructions. Quat Sci Rev 142:164-172. https ://doi.org/10.1016/j.quascirev.2016.04.020

Larsson L (2014) CDendro \& CooRecorder program package for tree ring measurements and crossdating of the data, version 9.4. https ://www.cybis.se/forfun/dendro.

Linderholm HW et al (2010) Dendroclimatology in Fennoscandiafrom past accomplishments to future potential. Clim Past 6:93114. https://doi.org/10.5194/cp-6-93-2010

Linderholm HW, Björklund J, Seftigen K, Gunnarson BE, Fuentes M (2015) Fennoscandia revisited: a spatially improved treering reconstruction of summer temperatures for the last 900 years. Clim Dyn 45:933-947. https://doi.org/10.1007/s0038 2-014-2328-9

Linderholm HW et al (2018) Arctic hydroclimate variability during the last 2000 years: current understanding and research challenges. Clim Past 14:473-514. https://doi.org/10.5194/cp-14-473-2018

Ljungqvist FC, Krusic PJ, Sundqvist HS, Zorita E, Brattström G, Frank D (2016) Northern Hemisphere hydroclimate variability over the past twelve centuries. Nature 532:94-98. https://doi.org/10.1038/ nature 17418

Ljungqvist FC et al (2019) European warm-season temperature and hydroclimate since $850 \mathrm{CE}$. Environ Res Lett 14:084015. https:// doi.org/10.1088/1748-9326/ab2c7e

Ljungqvist FC et al (2020a) Assessing non-linearity in European temperature-sensitive tree-ring data. Dendrochronologia 59:125652. https://doi.org/10.1016/j.dendro.2019.125652

Ljungqvist FC, Piermattei A, Seim A, Krusic PJ, Büntgen U, He M, Kirdyanov AV, Luterbacher J, Schneider L, Seftigen K, Stahle DW, Villalba R, Yang B, Esper J (2020b) Ranking of tree-ring based hydroclimate reconstructions of the past millennium. Quater Sci Rev 230:106074

Marvel K, Cook BI, Bonfils CJW, Durack PJ, Smerdon JE, Williams AP (2019) Twentieth-century hydroclimate changes consistent with human influence. Nature 569:59-65. https://doi.org/10.1038/ s41586-019-1149-8

McCarroll D, Pettigrew E, Luckman A, Guibal F, Edouard JL (2002) Blue reflectance provides a surrogate for latewood density of highlatitude pine tree rings. Arctic Antarctic Alpine Res 34:450-453. https://doi.org/10.1080/15230430.2002.12003516

McDowell N et al (2008) Mechanisms of plant survival and mortality during drought: why do some plants survive while others succumb to drought? New Phytol 178:719-739. https://doi.org/10.1 111/j.1469-8137.2008.02436.x

Melvin TM, Grudd H, Briffa KR (2013) Potential bias in 'updating'tree-ring chronologies using regional curve standardisation: re-processing 1500 years of Torneträsk density and ringwidth data. Holocene 23:364-373. https://doi.org/10.1177/09596 83612460791

Moberg A, Bergström H (1997) Homogenization of Swedish temperature data Part III: the long temperature records from 
Uppsala and Stockholm. Int J Climatol 17:667-699. https://doi. org/10.1002/(SICI)1097-0088(19970615)17:7\%3c667:AIDJOC115\%3e3.0.CO;2-J

Moberg A, Bergström H, Ruiz Krigsman J, Svanered O (2002) Daily air temperature and pressure series for Stockholm (1756-1998). Clim Change 53:171-212. https://doi.org/10.1023/A:1014966724 670

Rossi S, Deslauriers A, Anfodillo T, Morin H, Saracino A, Motta $\mathrm{R}$, Borghetti M (2006) Conifers in cold environments synchronize maximum growth rate of tree-ring formation with day length. New Phytol 170:301-310. https://doi.org/10.111 $1 / \mathrm{j} .1469-8137.2006 .01660 . x$

Rydval M, Larsson L- $\AA$, McGlynn L, Gunnarson BE, Loader NJ, Young GHF, Wilson R (2014) Blue intensity for dendroclimatology: Should we have the blues? Experiments from Scotland. Dendrochronologia 32:191-204. https://doi.org/10.1016/j.dendr o.2014.04.003

Rydval M et al (2018) Influence of sampling and disturbance history on climatic sensitivity of temperature-limited conifers. Holocene 28:1574-1587. https://doi.org/10.1177/0959683618782605

Seftigen K, Linderholm HW, Drobyshev I, Niklasson M (2013) Reconstructed drought variability in southeastern Sweden since the 1650s. Int J Climatol 33:2449-2458. https://doi.org/10.1002/ joc. 3592

Seftigen K, Björklund J, Cook ER, Linderholm HW (2015a) A treering field reconstruction of Fennoscandian summer hydroclimate variability for the last millennium. Clim Dyn 44:3141-3154. https ://doi.org/10.1007/s00382-014-2191-8

Seftigen K, Cook E, Linderholm H, Fuentes M, Björklund J (2015b) The potential of deriving tree-ring-based field reconstructions of droughts and pluvials over Fennoscandia. J Clim 28:3453-3471. https://doi.org/10.1175/JCLI-D-13-00734.s1

Seftigen K, Goosse H, Klein F, Chen D (2017) Hydroclimate variability in Scandinavia over the last millennium-insights from a climate model-proxy data comparison. Clim Past 13:1831-1850. https://doi.org/10.5194/cp-13-1831-2017
St. George S, Ault TR (2014) The imprint of climate within Northern Hemisphere trees. Quat Sci Rev 89:1-4. https://doi.org/10.1016/j. quascirev.2014.01.007

Toreti A et al (2019) The exceptional 2018 European water seesaw calls for action on adaptation. Earth's Future 7:652-663. https:// doi.org/10.1029/2019EF001170

Trnka M et al (2018) Priority questions in multidisciplinary drought research. Clim Res 75:241-260. https://doi.org/10.3354/cr01509

Vaganov EA, Hughes MK, Shashkin AV (2006) Growth dynamics of conifer tree rings: images of past and future environments. Springer-Verlag, Berlin, Heidelberg, New York. https://doi. org/10.1007/3-540-31298-6183

Vicente-Serrano SM, Beguería S, López-Moreno JI (2010) A multiscalar drought index sensitive to global warming: the standardized precipitation evapotranspiration index. J Clim 23:1696-1718. https://doi.org/10.1175/2009jcli2909.1

Wigley TML, Briffa KR, Jones PD (1984) on the average value of correlated time series, with applications in dendroclimatology and hydrometeorology. J Clim Appl Meteorol 23:201-213

Wilson R et al (2017) Experiments based on blue intensity for reconstructing North Pacific temperatures along the Gulf of Alaska. Clim Past 13:1007-1022. https://doi.org/10.5194/ cp-13-1007-2017

Yasue K, Funada R, Kobayashi O, Ohtani J (2000) The effects of tracheid dimensions on variations in maximum density of Picea glehnii and relationships to climatic factors. Trees 14:223-229. https ://doi.org/10.1007/PL00009766

Publisher's Note Springer Nature remains neutral with regard to jurisdictional claims in published maps and institutional affiliations. 